\title{
ESTUDO SOBRE A FIGURABILIDADE EM BALZAC: A DESFIGURAÇÃO DO RETRATO DE CAMILLE MAUPIN
}

\author{
Paula Caldas Frattini* \\ Universidade de São Paulo
}

\begin{abstract}
Resumo: Nesse artigo, a ideia corrente da leitura do descritivo em Balzac como uma "mania" estilística ou como a inscrição do mundo sensível no romance prefigurando, dessa feita, um romance de significação coerente e coesa, é reavaliada. A intenção, aqui, é sugerir ao leitor a análise de um elemento da poética balzaquiana - a figurabilidade - seus alcances estéticos e os possíveis problemas da relação entre o romance e as questões de representação. O retrato da personagem Camille Maupin do romance Béatrix desponta, dessa forma, como uma composição figurativa problemática referente à afirmação de que nos romances balzaquianos o que impera é uma representação fiel do mundo sensível. No lugar de uma reprodução fiel, notamos uma reconfiguração do corpo sensível. Na esteira do estudo de Georges DidiHuberman sobre a semelhança informe em George Bataille e o conceito batailliano de materialismo, propomos a leitura do corpo de Camille Maupin como a descrição de um corpo informe, priorizando a maneira como o texto ficcional balzaquiano torna a figura humana visível.
\end{abstract}

Palavras-chave: Balzac. Romance do século XIX. Figurabilidade.

\section{Introdução}

A figurabilidade balzaquiana, isto é, a sua produção figurativa diz respeito ao desejo e não somente à relação entre a escritura e os elementos plásticos. Mais especificamente, o desejo da escritura em tornar visível a figura humana, entendido, dessa forma, como o elemento figural e não figurativo na produção das figuras. Essa concepção do pensamento de Balzac sobre a figurabilidade é muito reticente nos paratextos, espaço em que o autor discute com frequência muitos aspectos filosóficos e teóricos de seu projeto literário. Há uma escassez nas formulações teóricas de Balzac em relação ao discurso figurativo e o pensamento

Esta obra está licenciada sob uma Creative Commons - Atribuição 4.0

\footnotetext{
* Possui doutorado em Letras obtido no Programa de Estudos Linguísticos, Literários e Tradutológicos em Francês da Universidade de São Paulo (2015) como bolsista CAPES e estágio doutoral desenvolvido na Université Paris Diderot - Paris 7 (2015), mestrado em Teoria Literária e Literatura Comparada (2010), também pela Universidade de São Paulo como bolsista CAPES, e graduação em Letras Modernas Francês/Português (1997) na mesma instituição. E-mail: <paulafrattini@hotmail.com>.
} 
estético balzaquiano, raro nos paratextos, é enunciado fundamentalmente na ficção, sobretudo nos romances em que a figura do artista entra em cena (DIAZ, 2011). O romance Le Chef d'œuvre inconnu ilustra muito bem a maneira como o discurso estético é assimilado na fatura do romance. As questões estéticas relacionadas à figurabilidade são enunciadas nos diálogos travados entre o pintor Nicolas Poussin e Frenhofer, personagem balzaquiano muito admirado por Cézanne e Picasso. José-Luis Diaz (2011) ressalta, também, que nos romances em que a figura do artista prevalece não há uma discussão versando apenas sobre a pintura, mas uma ampla reflexão sobre a irmandade ou rivalidade entre a literatura e as artes visuais.

É, portanto, no próprio texto ficcional, no esforço do traçado da figura na escritura que o texto de Balzac pensa a figurabilidade. Mas, antes de discutir o que pensa o texto balzaquiano sobre a figurabilidade, é essencial apontar alguns elementos mais conhecidos da produção figurativa balzaquiana, os quais se tornaram recorrentes em sua fortuna crítica. Em Théophile Gautier, por exemplo, encontramos algumas primeiras ideias do que estaria em voga na relação entre a escrita e o figurativo em Balzac. Retomando o estudo de T. Gautier, verificamos que ele destaca elementos da escrita balzaquiana já muito discutidos e que, de fato, caracterizam-na. Contudo, há também ideias não tão exploradas que se referem ao espaço do desordenamento.

Uma dimensão muito explorada até hoje da escritura balzaquiana, que já aparecia no texto de Gautier, é o esboço do tipo. Nesse texto sobre Balzac, Gautier elenca algumas características dos romances balzaquianos que não agradaram inicialmente aos críticos e leitores da época, entre elas, a minúcia e exageros dos detalhes na pintura do caráter das personagens, pois eram tidas como "prolongações fastidiosas". Tratava-se, no entanto, de elementos textuais novos e que haviam sido utilizados pelo autor da Comédia Humana no intuito de retratar a sociedade. Somente posteriormente, as descrições foram reconhecidas e admiradas como essenciais para a construção dos tipos (GAUTIER, 1859).

O termo tipo, que aparece na análise de Gautier, desvela aspectos sócio-históricos e representa a partir de uma apreensão tida como exata do real. A obra de Gautier sobre Balzac vem a público em 1859 e já prefigura o que, no final do século, Gabriel Tarde (1993) irá determinar como tipo social, o qual, na sua concepção, significa um sistema coerente que se repete e compõe uma civilização em particular.

O que chama a atenção no termo tipo, que começa a se construir no ambiente sóciohistórico do XIX, é a ideia de imitação, semelhança e coerência. Gabriel Tarde (1993), ao definir o tipo social, realiza uma comparação entre tipo e estampa; o tipo seria uma figura 
impressa a partir de uma estampa que nada mais é do que o modelo social. Segundo o sociólogo, a estampa estaria parcialmente impressa nos indivíduos e, em razão disso, o desenho produzido pela estampa poderia ser restituído apenas quando todas as impressões fossem confrontadas. Verificamos, portanto, que tal conceito estabelece uma relação de coerência entre a parte e o todo.

Théophile Gautier, por sua vez, ao esboçar a mania balzaquiana pelo tipo, não deixa de ressaltar o enquadramento no qual ele é feito na escritura, a saber, o distanciamento do ideal de beleza e aproximação do real. A insensibilidade de Balzac está relacionada diretamente ao referencial. Balzac não figura a partir de um modelo ideal de beleza. O referente, o modelo balzaquiano, é o homem do presente, o homem do século XIX. A normatividade da beleza clássica não interessava a Balzac e como relata-nos Gautier (1859), anedoticamente, o autor francês apreciava sem grande entusiasmo a Vênus de Milo, porém se avistasse uma bela parisiense vestida elegantemente diante da imortal estátua, tal figura real lhe provocaria o mais alto prazer estético.

De acordo com a análise de Gautier e a enunciação de Tarde, estamos, ainda, no plano da representação mimética: o artista reproduz o que está sob seus olhos. O plano da realidade é visto como plano de significação, o tipo é completamente legível e coerente em relação à figura do mundo sensível.

Mais tarde, Zola, no texto Différences entre Balzac et moi, iria reforçar o aspecto legível da semelhança, da significação social implicada na representação de costumes na obra de Balzac. A diferença entre eles, segundo Zola, estaria na amplitude dos projetos e no teor. A Comédie Humaine é vastidão, possui uma perspectiva ampla, horizontal, enquanto que Zola afirma que seus romances incidem no enfoque. O enquadramento de Zola é mais restrito (ZOLA, 1967). Quanto ao teor, Balzac trabalha no campo da história de costumes e da sociologia, enquanto que Zola se insere no plano científico. A leitura de Zola, tal como exposta aqui, não traz nenhuma novidade em relação ao que se costuma dizer sobre os projetos dos autores, acentuando-se ainda mais o caráter do tipo em Balzac. Contrariamente a Gautier, no entanto, Zola em nenhum momento traça paralelos entre a representação balzaquiana e as artes plásticas, no que respeita ao figurativo. Tudo se passa no campo do discurso social, como esperado. Entretanto, curiosamente Zola não utiliza o termo tipo. Ele emprega em seu lugar a palavra figura (ZOLA, 1967).

Como vimos, nada se falou acerca da figurabilidade, isto é, do trabalho na escritura sobre o figural que se refere à intensidade produzida pelo desejo. No entanto, Gautier (1859) 
já tateia o desarranjo que está na força do olho balzaquiano, no espaço do figural que desarticula a reprodução exata do real, ao constatar que essa operação da escritura, sua figurabilidade, não acontece sem a convulsão da luta entre a forma e a ideia.

Ainda no mesmo ano, Baudelaire, em um texto dedicado a Gautier, retoma a questão da convulsão em Balzac, ou seja, da luta entre forma e ideia, desestabilizando a relação entre modelo e cópia ou tipo e sociedade como vimos até agora. No entendimento de Baudelaire, existia uma verdadeira convulsão provocada pelo excesso nas figuras criadas por Balzac. Como este último desejava tudo ver, adivinhar e fazer com que seus leitores também fossem capazes de apreender a verdade escondida, Balzac intensificava os detalhes da figura e incorporava o excedente na sua versão final. O que poderia ser considerado como defeito, era para Baudelaire (1859), a força do texto balzaquiano.

Baudelaire, definitivamente, é quem destaca o espaço figural na representação balzaquiana. $\mathrm{O}$ defeito, o rabisco, transforma-se em qualidade para quem figura o mundo exterior com o olho do espírito. Porém, paradoxalmente, haja vista que aí se concentram identificações estéticas e ideológicas diferentes, Théophile Gautier e Baudelaire aproximamse quando pensam sobre a representação figurativa em Balzac ao partirem da mesma fonte: a materialidade, conceito que retomarei mais adiante.

Após esse breve panorama, notamos que o trabalho de figuração de Balzac é dissonante, mas não totalmente diferente do arcabouço contemporâneo. A dissonância é, segundo minha leitura, a dialética da força libidinal em ato - a convulsão da figura, como na acepção de Baudelaire - e do traço figurativo legível e coerente presente no texto balzaquiano.

É a convulsão da figura que pretendo explorar nesse artigo, se o tipo é trabalhado nos moldes da semelhança e da forma, a convulsão da figura, contrariamente, aproxima-se da dessemelhança e da desfiguração. Veremos que a construção figurativa, em Balzac, não está completamente comprometida com a História, o que se poderia mais frequentemente esperar, talvez, de um romance de obediência realista.

Mas de que se trata a desfiguração? A que nos referimos quando pensamos em desfiguração? Antes, é preciso ter em mente que tanto a desfiguração quanto a figuração compõem o trabalho figurativo, ou seja, a figurabilidade.

Para ilustrar a convulsão da figura, analiso o retrato de Camille Maupin do romance Béatrix, quase como em um movimento mimético à escritura balzaquiana, na medida em que destaco os aspectos da desfiguração em ato. E pela análise do longo retrato, o qual ocupa um 
considerável espaço na trama narrativa, podemos verificar esse trabalho de figurabilidade, a desfiguração, em oposição ao elemento figurativo, em outras palavras, da correspondência da figura realista e o mundo sensível.

\section{A desfiguração no retrato de Camille Maupin}

A monstruosidade do retrato de Camille Maupin está associada à questão da desfiguração e da dessemelhança que a escritura balzaquiana já questionava na produção figurativa, de maneira que, não sem estranhamento, mas postulando uma leitura crítica na qual a noção de anacronismo está articulada, o retrato de Camille Maupin apresenta uma montagem figurativa. Analisemos, então, de que maneira a monstruosidade e a montagem são trabalhadas nesse retrato.

Primeira consideração: o retrato produz uma semelhança irritante. E por que irritante? Irritante no sentido de inquietação, de insubordinação: não se trata de um retrato adequado. Há algo em sua descrição que irrita, pois sua semelhança está além do esperado, do comum. O retrato, no qual a semelhança é trabalhada, exige também do leitor o mesmo trabalho.

A que figura humana se assemelha Camille Maupin? Procurar uma resposta adequada a essa pergunta, sobretudo em se tratando de uma escritura de moldes realistas que representaria o mundo sensível, é o que se espera; entretanto, ela mostra-se insuficiente: a adequação é justamente desfeita nesse retrato. Nele, o que ocorre é uma desestabilização de sua materialidade e, por esse motivo, a dificuldade em compará-lo à figura do mundo sensível. A dificuldade é provocada pelo excesso de semelhanças que tornam a figura informe. (DIDI-HUBERMAN, 1995).

Comecemos por esse mal-estar. O leque de semelhanças acumulado no retrato desestabiliza a significação e atribui, igualmente, a monstruosidade ao retrato. Ele, além disso, é recortado: suas partes não estão necessariamente relacionadas com um todo de maneira coerente. O recorte corresponde à decomposição, à desfiguração humana pela montagem figurativa.

Além da multiplicidade de referências plásticas, no retrato - tais como escultura e pintura, divergência de proporções, baixo-relevo, proporções monumentais e diminutas, referências às obras artísticas de épocas e culturas diferentes (e é preciso ressaltar que todo esse excesso referencial por si só já bastaria para falarmos de seu aspecto disforme) -, há, também, um excesso e uma irritação na linguagem. Quero dizer com isso que a linguagem estaria aliada a uma espécie de crueldade na decomposição do corpo, trabalhando sua 
descrição num vaivém entre as formas ideais de beleza e seu contrário.

O movimento das formas é o que define o aspecto do informe, pois o informe não é, como enuncia Didi-Huberman, a negação da forma, nem a ausência dela. O informe é, na verdade, a "movimentação das formas" (DIDI-HUBERMAN, 1995, p. 134, tradução minha). Passamos, então, da convenção das formas que trabalharam no código referencial, para esse outro movimento das formas, a "dança da semelhança" no materialismo do corpo.

Notaremos que o corpo é segmentado, não de acordo com as regras convencionais da descrição do retrato, afinal, é regra a apreensão descritiva por partes, sendo, normalmente, efetivada de maneira descendente: em primeiro lugar, é descrito o rosto, em seguida, descemos para o busto, para as pernas, compondo, finalmente, o todo da figura. Tal movimento não é o que ocorre no plano descritivo do retrato de Camille. Nele, o corpo é talhado pela escritura e cada parte é trabalhada na potencialidade de suas formas.

O informe é a consequência do poder das formas da figura humana. Assim sendo, como enunciado por Didi-Huberman (1995), assistimos na movimentação das formas a dialética da semelhança e da dessemelhança na figura humana, pois a forma não é um aspecto idealizado. Essa é a diferença, por exemplo, entre a articulação do descritivo balzaquiano no retrato e o figurativo. Se fundamentado por um materialismo idealizado, a forma é acadêmica, rígida, enquanto que, no materialismo que Bataille denominará "demente", a forma se abre e se justapõe. O resultado é a semelhança informe, a semelhança do excesso e, na figurabilidade balzaquiana, encontramos o mesmo excesso e o mesmo movimento - a dialética da semelhança e da dessemelhança - em um único retrato, como é o caso do de Camille Maupin.

O materialismo balzaquiano tem traços da "demência", tal como denomina Bataille, pela intensidade; obviamente, há diferenças concretas entre as duas escrituras, mas o traço e o trabalho com o estilo aproximam-se. No texto "Matérialisme", Bataille (1929) aponta os entraves do materialismo entendido sob a ótica idealista, a qual embora tente eliminar qualquer traço de espiritualidade é incapaz de se desprender de uma ordem hierárquica e convencional, continuando a promover, dessa maneira, a busca da forma idealizada, ou seja, como a matéria deveria ser.

Isso posto, não deveria ser a forma de Camille Maupin, seguindo os padrões ideais da musa, delicada, feminina, uma forma agradável de observar, isto é, uma forma sem perturbações? Não deveria ser um corpo, mesmo que dividido, hierarquizado em suas partes em harmonia com o todo? Se assim fosse, na forma como ela deveria ser, seriam 
pormenorizados os aspectos fisiológicos? Não obtemos nenhuma resposta afirmativa a essas questões no retrato de Camille e é nesse sentido que o estilo da composição trabalhada pela figurabilidade na escritura balzaquiana se aproxima da semelhança informe.

Assim, o primeiro talhe da figura de Camille Maupin é seu rosto:

Le jour glisse sur cette peau comme sur un corps poli, il y brille; une émotion violente est nécessaire pour que de faibles rougeurs s'y infusent au milieu des joues, mais elles disparaissent aussitôt. Cette particularité prête à son visage une impassibilité de sauvage. (BALZAC, 1976, p. 693). ${ }^{1}$

Nada da absoluta delicadeza esperada no retrato da musa: inesperadamente, o rosto é semelhante ao de um selvagem. Outro talhe são os olhos: 'Dans un moment de passion, l'œil de Camille Maupin est sublime : l'or de son regard allume le blanc jaune, et tout flambe ; mais au repos, il est terne, la torpeur de la méditation lui prête souvent l'apparence de la niaiserie [...]. (BALZAC, 1976, t. II, p. 694)."2

Os olhos em repouso têm a aparência da estupidez, semelhança estranha para uma mulher dita brilhante. Desses aspectos menos fisiológicos, porém bárbaros nas contradições, o descritivo atém-se às partes do corpo, literalmente, e o burlesco da montagem figurativa é o que chama a atenção: "Os cílios são curtos, mas densos e negros como caudas de arminho" (BALZAC, 1954, p. 219). A visão dos cílios semelhantes à cauda de um arminho causa um estranhamento; a comparação com o conceito da pele associado ao animal até poderia parecer mais aceitável, pela beleza, delicadeza e feminilidade da vestimenta, mas a imagem é explícita, desproporcional e a montagem entre o olho humano e a cauda do animal é, de fato, burlesca, desfigurando a parte humana.

De elementos normalmente trabalhados no retrato de uma mulher, tais como rosto, olhos, maçãs do rosto, a descrição estaciona no nariz:

Le nez, mince et droit, est coupé de narines obliques assez passionnément dilatées pour laisser voir le rose lumineux de leur délicate doublure.

[...] Là surtout, comme l'a remarqué Talma, se peint la colère ou l'ironie des grandes âmes. L'immobilité des narines accuse une sorte de sécheresse. Jamais le nez d'un avare n'a vacillé, il est contracté comme la bouche; tout est clos dans son visage comme chez lui.(BALZAC, 1976, t. II, p. 694-695). ${ }^{3}$

\footnotetext{
${ }^{1}$ A luz desliza sobre essa pele como por sobre um corpo polido, brilhando; é necessária uma emoção violenta para que débeis rubores se infundam nas faces, mas logo desaparecem. Essa particularidade dá-lhe ao rosto uma impassibilidade selvagem. (BALZAC, 1954, p. 219).

${ }^{2}$ Num momento de paixão, os olhos de Camilo Maupin são sublimes; o ouro de seu olhar acende o branco amarelo e tudo flamba; mas em estado de repouso é embaciado, o torpor da meditação empresta-lhe muitas vezes a aparência da tolice [...]. (BALZAC, 1954, p. 219).

${ }^{3} \mathrm{O}$ nariz fino e reto é cortado por ventas oblíquas, bastante apaixonadamente dilatadas para deixar ver o róseo luminoso de seu delicado interior. [...] aí principalmente, como o notou Talma, pinta-se a cólera ou a ironia das grandes almas. A imobilidade das ventas indica uma espécie de secura. Jamais o nariz de um avarento vacila, ele é contraído como a boca; tudo no seu semblante é fechado como nele. (BALZAC, 1954, p. 220).
} 
Falar das especificidades da parte interna do nariz e realizar uma digressão sobre a relação entre a mobilidade do nariz e a avareza, parece-me uma contradição acentuada no retrato da musa, sobretudo pelo baixo materialismo da frase que fala do nariz do avaro: "ele é contraído como a boca; tudo no seu semblante é fechado como nele." O processo de desfiguração desse corpo feminino incide, então, sobre a presença de elementos masculinos no rosto de Camille: "Il est nécessaire de dire que le dessous du nez est légèrement estompé par un duvet plein de grâce. La nature aurait fait une faute si elle n'avait jeté là cette suave fumée.” (BALZAC, 1976, t. II, p. 695). ${ }^{4}$

Se pensarmos no idealismo presente no materialismo, não seria necessária a figuração do buço no rosto de Camille, ainda mais pelo fato de o retrato não ser irônico; mas esse detalhe, aliado ao estilo do quadril da musa, mais parecido ao de Baco que ao de Vénus, intensifica o caráter de desfiguração e de intensa montagem figurativa do retrato:

La chute des reins est magnifique, et rappelle plus le Bacchus que la Vénus Callipyge. Là, se voit la nuance qui sépare de leur sexe presque toutes les femmes célèbres, elles ont là comme une vague similitude avec l'homme, elles n'ont ni la souplesse, ni l'abandon des femmes que la nature a destinées à la maternité ; leur démarche ne se brise pas par un mouvement doux. Cette observation est comme bilatérale, elle a sa contre-partie chez les hommes dont les hanches sont presque semblables à celles des femmes quand ils sont fins, astucieux, faux et lâches. (BALZAC, 1976, t. II, p. 695). ${ }^{5}$

\section{Considerações Finais}

Se compararmos o retrato de Camille Maupin ao de Madame Firmiani - personagem epônimo de um romance de Balzac -, por exemplo, podemos verificar a diferença entre a montagem figurativa e a forma como ela deveria ser. Nesse sentido, o corpo no retrato de Madame Firmiani é permeável às convenções ou ideais e beleza. O espaço externo interfere na construção da beleza de Madame Firmiani, contaminando a figuração. Desse modo, o retrato, contaminado pelo senso comum do que se espera de uma bela mulher, apresenta uma normatividade:

Par un de ces hasards qui n'arrivent qu'aux jolies femmes, elle était dans un moment où toutes ses beautés brillaient d'un éclat particulier, dû peut-être à la lueur des

\footnotetext{
${ }^{4}$ É necessário dizer que a região inferior ao nariz é levemente obscurecida por uma penugem muito graciosa. A natureza teria cometido um erro, se não tivesse atirado ali aquela suave fumaça. (BALZAC, 1954, p. 220).

${ }^{5}$ A cintura é magnifica e lembra mais o Baco do que a Vênus Calipígia. Vê-se por aí a diferença apenas sensível que separa quase todas as mulheres célebres de seu sexo; elas têm nesse ponto como uma vaga semelhança com o homem, não tem nem a flexibilidade, nem a moleza das mulheres que a natureza destina à maternidade; seu caminhar não se amacia por um movimento suave. Essa observação é como que bilateral, tem seu reverso nos homens, cujos quadris são quase semelhantes aos das mulheres, quando são finos, astuciosos, falsos e cobardes, (BALZAC, 1954, p. 220).
} 
bougies, à une toilette admirablement simple, à je ne sais quel reflet de l'élégance au sein de laquelle elle vivait. [...] Il est un moment où, contente de sa parure, où se trouvant spirituelle, heureuse d'être admirée en se voyant la reine d'un salon plein d'hommes remarquables qui lui sourient, une Parisienne a la conscience de sa beauté, de sa grâce; elle s'embellit alors de tous les regards qu'elle recueille et qui l'animent, mais dont les muets hommages sont reportés par de fins regards au bienaimé. En ce moment, une femme est comme investie d'un pouvoir surnaturel et devient magicienne; coquette à son insu, elle inspire involontairement l'amour qui l'enivre en secret, elle a des sourires et des regards qui fascinent. Si cet état, venu de l'âme, donne de l'attrait même aux laides, de quelle splendeur ne revêt-il pas une femme nativement élégante, aux formes distinguées, blanche, fraîche, aux yeux vifs, et surtout mise avec un goût avoué des artistes et de ses plus cruelles rivales! (BALZAC, 1976, t. II, p. 149). ${ }^{6}$

O objetivo dessa breve comparação entre os retratos de Camille Maupin e Madame Firmiani é desarticular uma leitura crítica que, como vimos, surge no século XIX e permanece até hoje como referencial obrigatório nos estudos dos romances balzaquianos, ou seja, o entendimento de um projeto literário sustendado pela representação do real, a tipologia do homem oitocentista e a apreensão da História que esteticamente produzem o retrato figurativo.

Ora, de fato Balzac produz a figura a partir de uma estética relacionada ao materialismo. No entanto, não se trata apenas do materialismo convencional, preocupado em dimensionar uma figura que poderíamos identificar rapidamente no mundo sensível ou, ainda, que seguiria os códigos convencionais de beleza ou sociais da época.

No retrato de Madame Firmiani, Balzac articula tais códigos na criação da figura, mas ao fazê-lo expõe ao leitor os artifícios da construção. Mesmo se tratando de uma figura feminina ideal e convencional, que se repete nos romances de costumes, o narrador desvela ao leitor quais códigos ele utiliza para torná-la uma mulher admirável. É o local apropriado ("salão cheio de homens notáveis"), a luz correta ("todas as suas belezas brilhavam com um esplendor particular, talvez devido ao clarão das velas"), o traje adequado ("uma toilette admiravelmente simples"), segundo os costumes da época, que a tornam ideal. Não encontramos uma montagem figurativa, porém uma gesticulação narrativa explícita em torno

\footnotetext{
${ }^{6}$ Por um desses acasos, que só acontecem às mulheres bonitas, ela se achava num momento em que todas as suas belezas brilhavam com um esplendor particular, talvez devido ao clarão das velas, a uma toilette admiravelmente simples, a não sei que reflexo da elegância em cujo seio ele vivia. É preciso ter estudado as pequenas revoluções de uma recepção nos salões de Paris para apreciar as matizes imperceptíveis que podem colorir um rosto de uma mulher e transformá-lo. Há um momento em que, satisfeita com os seus adornos, achando-se espirituosa, feliz por ser admirada, ao ver-se rainha de um salão cheio de homens notáveis que lhe sorriem, uma parisiense tem consciência de sua beleza, de sua graça; ela se embeleza então com todos os olhares que recolhe e que a anima, mas cujas mudas homenagens são entregues por um olhar sutil ao bem amado. Nesse momento a mulher está como investida de um poder sobrenatural e torna-se uma adorável feiticeira; coquete sem o querer, inspira involuntariamente o amor que a embriaga em segredo e tem olhares e sorrisos que fascinam. Se esse estado, que vem da alma, dá atrativos, mesmo às feias, de que esplendor não revestirá ele uma mulher nativamente elegante, de formas distintas, alva, fresca, de olhos vivos, e, sobretudo, vestida com um bom gosto confessado pelos artistas e por suas mais cruéis rivais! (BALZAC, 1954, p. 435-436).
}

Anu. Lit., Florianópolis, v. 21, n. 2, p. 134-144, 2016. ISSNe 2175-7917 
dos códigos culturais que tenciona o que se convencionou denominar o "retrato figurativo balzaquiano", como uma extensão da figura tal como esta se encontraria no mundo sensível.

Já na desfiguração do retrato de Camille Maupin, pelo excesso de semelhança trabalhado na montagem figurativa, notamos uma dialética da semelhança e dessemelhança, justaposições e contradições figurativas que sugerem aproximações com o surrealismo e o informe que será trabalhado por Georges Bataille. Para concluir, a questão da figurabilidade, mais especificamente, em como a figura humana se torna visível no texto balzaquiano, possibilita um entendimento estético mais apurado e a visibilidade das nuances de um projeto literário não apenas realista, mas também de uma expressão literária do corpo, de seu materialismo e de suas potencialidades.

\section{Referências}

BALZAC, Honoré de. La Comédie Humaine. Édition publié sous la direction de PierreGeorges Castex. Paris: Gallimard, «Pléaide », t. II, 1976.

BALZAC, Honoré de. A Comédia Humana. Introduções, notas e orientação de Paulo Rónai. Rio de Janeiro: Editora Globo, v.2 e 3, 1954.

BATAILLE, Georges. "Matérialisme”. Documents, Paris, n. 3. p. 170, 1929.

BAUDELAIRE, Charles. Théophile Gautier. Paris: Poulet-Malassis et de Broise, 1859.

DIAZ, José-Luiz. « Du feu dans le feu » Quand « l'art littéraire » balzacien se mesure à la peinture, L'Année balzacienne, Paris, n. 12, p. 79-96, 2011/1. Disponível em: http://dx.doi.org/10.3917/balz.012.0079. Acesso em: 17 fev. 2014.

DIDI-HUBERMAN, Georges. La Ressemblance Informe ou le gai savoir selon Georges Bataille. Paris: Macula, 1995.

GAUTIER, Théophile. Honoré de Balzac. Paris: Poulet-Malassis et de Broise, 1859.

TARDE, Gabriel. Les Lois de L'Imitation. Paris: Éditions Kimé, 1993.

ZOLA, Émile. Différences entre Balzac et Moi. Les Rougon-Macquart. Paris : Gallimard, 1967, t. V, (Bibliothèque de Pléiade).

[Recebido em 3 de julho de 2016 e aceito para publicação em 30 de setembro de 2016]

\section{A study on Balzac's figurability: The disfiguration of Camille Maupin's retrato}

Abstract: In this article, the current idea of reading the descriptive in Balzac's novels as a stylistics "mania" or as the inscription of the sensible world in the text, thus, prefiguring a 
novel with a coherent and cohesive signification is re-evaluated. The intent here is to suggest to the reader an analysis of a poetic element in Balzac's work - the figurability - its aesthetic achievements and possible problems in the relationship between the novel and the representation issues. Camille Maupin's portrait, a character of the novel Béatrix, thus appears as a problematic figurative composition regarding the affirmation that in Balzac's novels the key characteristics are a faithful representation of the common world. Instead of this faithful reproduction, we notice a reconfiguration of the sensible body. Following chiefly Georges Didi-Huberman's study about the formless resemblance in Georges Bataille and the Battailean concept of materialism, we suggest the reading of the Camille Maupin's body as a description of a formless body, prioritizing how Balzac's fictional text makes the human figure visible.

Keywords: Balzac. Nineteenth-century novel. Figurability.

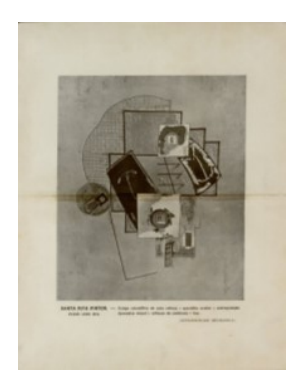

